\title{
Problem and Countermeasure on Mental Health Education for College Students
}

\author{
Shuang Wei \\ School of Education and Sports, Bohai University, Jinzhou, 121013, China \\ wsbd2000@163.com
}

Keywords: college students; mental health; education; problem; countermeasure

\begin{abstract}
University stage is the golden period of the development of life, mental health is the premise of scientific and cultural knowledge of College students. Strengthening the mental health education of college students is an important way to promote the healthy growth of college students and cultivate the qualified builders and successors of the socialist cause under the new situation. This paper expounds the importance of College Students' psychological health education, analyzes the problems of College Students' psychological health education, and puts forward the Countermeasures of College Students' psychological health education. The specific countermeasures include: exploring the methods of mental health education, attaching importance to the education of special groups, combining with the family education, improving the quality of the educators and adapting to the rapid development of the network. College Students' mental health education is a complicated systematic project, which has been gradually standardized, institutionalized and scientific.
\end{abstract}

\section{Introduction}

Contemporary college students are in the period of social transformation, college students are facing growing increasing social pressure, in study, life and social adaptation encountered more and more difficulties and setbacks, lead to the emergence of a variety of psychological problems and improve the mental health of college students forced in urgent. College Students' mental health education is not only the necessary means to solve the psychological problems of college students, but also an important way to achieve the goal of college education [1]. To strengthen the psychological health education of college students is under the new situation to promote the healthy growth of students and cultivate top-notch innovative personnel is an important way, is an important measure to fully implement the party's education policy, building a country rich in human resources, is to promote the reform of higher education, strengthen and improve College Students Ideological and political education of the important task. The study of College Students' psychological problems and education can further in-depth understanding of the current situation of the psychological health education for college students, as the future direction of College Students' psychological health education work; It can provide useful experience and reference model for the college student mental health education practice; It can provide a reference for the education departments at all levels, for further strengthening and improving college students' psychological health education work, formulating relevant policies and measures. The results of this study, to strengthen the psychological health education of college students, reduce the negative influence brought by the educational concept, management system and individual cognition, deepen understanding of the laws governing the development of human psychology, and to further meet the needs of College Students' psychological health under the current social environment development and lays the foundation to put forward a more scientific and rational psychology and education ideas and theories.

\section{Importance on Mental Health Education for College Students}

College students are a group with a higher level of knowledge, the future of the country, the hope of the nation, and the successor of the socialist cause. The mental health of college students is not only 
related to the future of the individual, but also to the socialist modernization construction of our country.

(1) The need for healthy growth of College students. The desire of college students is strong, and estimates are too high, the family and social expectations are too large, psychological development is not yet fully mature. Especially the study pressure, economic pressure, employment pressure, competitive pressure, emotional stress, and so on. There are a lot of problems in the aspects of environmental adaptation, self-management, ideal reality, learning and success, dating, love, job hunting and emotion regulation. Unhealthy psychological state makes the mental work of college students will be unable to use their wisdom to learning, cannot be successfully completed the task of learning. It will be the family's great burden, also a great waste of countries. The mental health of college students is facing the potential threat, which is directly related to the comprehensive development and early success.

(2) The need of Ideological and political education [2]. Mental health education to solve the psychological problems, ideological and political education is the social use of a certain political views and moral norms, the impact of the purpose, so that students have the social needs of the ideological and moral. Nowadays, many college students' ideological problems are common and psychological factors, which need to advance with the times, constantly innovate, strengthen the training of psychological quality in the original education mode. The traditional ideological education to the students' problems is simply due to the ideological problems, focusing on the theory of education, ignoring the differences between college students and the growth environment. And it is closely related to the physical and mental development of student's psychological health education. In the process of education to students and establish mutual trust relationship, frustration and confusion as the common problems of growth and development of college students, teachers and students together in the face of these difficulties, students are more likely to accept the teachers teach.

(3) The need for a comprehensive implementation of quality education. Quality education refers to the education mode which aims at improving the quality of all aspects of the education. It takes people's ideological and moral quality, ability training, personality development, physical health and mental health education. The full implementation of quality education is to cultivate the spirit of innovation and practical ability of students, improve the students' psychological quality, and create ideals, morality, culture, discipline, moral, intellectual and physical development of socialist builders and successors. College students have no good psychological quality, cannot adapt to the needs of social development, it is difficult to take the task of the socialist cause, psychological quality education is the starting point of quality education. It is an important task for higher education to strengthen mental health education, optimize the psychological quality of college students, and promote the comprehensive quality of talents.

\section{Problem on Mental Health Education for College Students}

Under the condition of market economy, college students' psychological health education work facing more complicated environment, psychological health education work shoulder heavy responsibilities, faced with many challenges. The existing problems mainly focus on the following aspects $[3,4]$ :

(1) The system of mental health education mechanism is not perfect. The mechanism of College Students' mental health education is under the guidance of Ideological and political education system, in order to promote college students' all-round development and promotion of Ideological and moral awareness and practical ability, school departments, organizations and individuals such as education mechanism between the elements, interrelated, interaction and restrict each other and collaboration, the formation of dynamic operation mode, structure and specific methods of operation system of system. Lack of education awareness of the staff the current mental health education, mental health education has been isolated, mental health education institutions and schools to other departments and exchange opportunities less, only rely on psychological health 
education, professional personnel, lack of unified arrangements between the various departments, not effectively integration advantages of resources. Lack of effective supervision and evaluation of mental health education, but also to the relevant departments and personnel to ignore the psychological health education.

(2) The moral education of mental health education. The mental health education of college students is an important part of the work of moral education in Colleges and universities in the new form, the form and content of the two are not exactly the same. But in the practice of university education, the phenomenon of mental health education and moral education is the same, which is equal to the moral education. Teachers of mental health education is the basic moral education teacher and political cadres, ideological often with the goal of moral education requires students, in psychological guidance and counseling is difficult to avoid the orientation of moral education, the psychological problems of students from the ideological and moral aspects of the analysis, to the moral law instead of scientific analysis. Mental health education and moral education are closely related, are facing all students, promote the comprehensive development of students and healthy growth. But both of the two systems, starting point, principles and methods are not the same, simply using moral education methods to carry out mental health education, or the psychological problems as moral problems are not appropriate.

(3) Lack of social support system. Social psychology believes that the growth of individual is influenced by external environment, and the personality characteristics and environment are the behavior of individuals. Individual's social environment and cultural background are the key factors of individual growth. Healthy psychological quality cannot be through a course on the training, mental health education is a systematic project, need comprehensive educational environment, require schools to each department and cooperate with each other, various disciplines mutual coordination, and family and social full penetration, the school has the mental health education and the discipline education separated, school education and family education and social education split apart, psychological health education is lack of effective social support system, it is difficult to get ideal effect.

\section{Countermeasure on Mental Health Education for College Students}

The social development has brought the new contradiction and the question to the university student psychologically healthy education. The university student psychological health education is still in the exploration, has not formed the independent complete system structure. College Students' mental health education is a complicated systematic project, which needs the joint efforts of school, society, parents and students. As the guide of College Students' mental health education, colleges and universities must combine the characteristics of the psychological development of college students in the new era, and establish a new concept of the value of mental health education, and reform the educational model. In the continuous exploration of the psychological health of college students to gradually take the road of standardization, institutionalization and scientific. Through in-depth analysis, this paper improve the psychological health education of college students are as follows [5-8]:

(1) Exploring methods of mental health education. Mainly can adopt the following four ways: first, the psychological measurement technology, with the scale of the form of quantitative or quantitative, the individual's some psychological phenomenon or performance behavior is described. Scientific analysis of the measurement data, scientific evaluation of College Students' psychological status; second, psychological intervention by psychology intervention problem generated by the object and psychological activity, were to intervene, change in the direction of an intended. Let the students by virtue of their own strength to resolve contradictions, control problems, conflicts into other areas, make students full of hope for the future; third, self-help mental health education, to enable students in a variety of ways to make their own psychological needs to reach the state of satisfaction. This method solves the lack of mental health education workers, and in accordance with the characteristics of college students, let students learn to adjust their mentality and emotion, fulfill their curiosity, and improve the learning enthusiasm; Fourth, group counseling mental health 
education, let the students into the real state, in imparting knowledge of the theory of psychology at the same time, fully cited cases, so that students participate in the analysis and summary of the case. To guide students to the failure of the experience as the last failure, increase security, improve self-confidence.

(2) Pay special attention to the education of special groups. There are several special groups in college students, different from the ordinary university students, special groups need more care. Psychological health education cannot ignore the demands of this part of the group. In addition to the use of conventional methods, but also need to choose according to their characteristics of targeted measures in order to achieve the purpose of promoting mental health. Mainly include four categories: the first category, female college students. To increase the ability to open some of the female college students to develop their potential, enhance their sense of responsibility and self-confidence, so that they give full play to the gender advantage in a specific area. To guide the female college students to establish a positive belief, enhance their confidence and strength, to help them face the reality objectively, in order to cultivate the psychological quality and psychological problems. The implementation of gender differences in education, strengthening the cultivation of female college students' creative ability and practical ability. Cultivate their perseverance and persevere, never yield in spite of reverses firm and indomitable spirit; second, the poor college students. Poor college students due to the economic situation of the restrictions, to bear the greater psychological pressure. Take effective measures to help them alleviate the psychological burden, so that poor students in a positive, healthy, dynamic state into the University life. Guide the impoverished college students correct understanding of poverty and poverty as a stepping stone for the development of life, make poor students turn a negative into a positive, change from passive to active. Student cadres should take the lead, lead other students to give emotional support to poor students, they feel the environment, understand their inner feelings, to provide them with help. The third category, disabled students. The characteristics of physical and mental development of students with disabilities and ordinary college students have more differences. Have a strong sense of inferiority, communication barriers, self-close, strong self-esteem, reaction sensitivity, dependence and other characteristics. Timely psychological communication and counseling to them, to ease their psychological pressure and trouble. The creation of some of the problems of living close to students with disabilities, to encourage them to play a subjective initiative, learn to cope with the crisis of life independently. Fully explore the potential advantages of students with disabilities, the unfavorable factors into favorable factors. The positive influence of the disabled college students by example demonstration method; Fourth, the "child prodigy" of College students. Due to the lack of the social soil of healthy growth, "child prodigy" students prematurely into the adult world, the outside world is too concerned about their grades, but ignore their inner world. Focus on the "child prodigy" intellectual development at the same time, pay attention to their social and psychological cultivation. In a timely manner to teach life self-care, cultivate emotion, interpersonal fusion techniques, improve ability to adapt to society, correct biased idea, make them psychologically can withstand the test from the Chinese side of the life aspect, promote a "child prodigy" college students to grow up as a normal person.

(3) Combined with family education. Family education through the concept of family education, education, environmental education and parental mental health level, for college students in the home range, conscious education and exerts a subtle influence. As a component part of education, family education is the foundation of school education and social education. It is a supplement and extension of both. It is a lifelong education. Compared with the school education and social education, family education has the characteristics of education content, the way of life, the way of emotional, diversification and so on. To promote the development of College Students' mental health, we should make a rational analysis of the family education from the understanding, and constantly change the educational concept according to the actual needs, so that the good efficacy of family education will be actively promoted. School to organize the necessary and consciously to parents for training, teach related knowledge of family education theory, strengthening of family education parents correctly, after giving their children basic material and spiritual needs, at the same 
time, with the development requirements of the times, understanding of family education in the presence of errors in education, education idea and education mode were corrected in a timely manner. Enrich the content of family education, cultivate students' good habits, healthy lifestyle, self-education and management ability. Master the principles and skills of interpersonal communication, learn how to deal with the problems that are often encountered in interpersonal communication. Focus on physical and mental health education, and actively carry out the necessary physical exercise, develop a healthy lifestyle, improve their psychological defense mechanism, to ensure the healthy development of physical and mental. Efforts to create a democratic, equal, caring, harmonious family atmosphere, so that children feel and experience the magic and beauty of life, learn to respect life and cherish life. For emotional education, cultivate children's safety feeling, a sense of trust, sense of responsibility and the sense of pride, to teach kids to take care of others, love all the good things, let the children form emotional health in exert a subtle influence on the practice and natural feeling experience.

(4) Improve the quality of educators. The quality of College Students' psychological health education determines the level of College Students' psychological health education. We must build a contingent of teachers with high quality mental health education, and promote the standardization and scientific of psychological health education in Colleges and universities. Specific measures include three aspects: first, the formation of professional teachers. The establishment of full-time teachers, the development of mental health education teachers and professional title promotion system, to attract more psychology and education teachers to join the ranks of mental health teachers; the two is to strengthen the training of professional theory and skills. Through training, abundant education of psychological health education theory knowledge, improve the psychological counseling and counseling skills, combine theory with practice, use scientific theory to guide the work of mental health education; third, to establish the system of the qualification certificate. Mental health education teachers should also pass the examination, access to mental health education services qualification certificates, try to avoid nonprofessionals are not standardized education.

(5) To adapt to the rapid development of network. Network to the students bring new knowledge, and new technology at the same time, it also brings some network rubbish culture, destroyed the original good morality and make some students from going astray. To create a good cultural atmosphere of the campus network, to build a good environment for college students' mental health education. To help students understand the network civilization, familiar with the network technology, explore the network potential, so that the network has become a tool for learning and progress. Develop an interest in the transfer of network attention, training students a variety of interests and hobbies. Enhance network self-control, training and self-regulation, set an example of strength, strengthen their own learning, develop good habits, and cultivate their positive and healthy mentality. In the colorful campus cultural activities into the network in the knowledge of mental health, in imperceptible on College Students' implementation of network psychological health education, make mental health education not stick to one pattern in the network, the network psychological health education to get a better effect.

\section{Conclusion}

Mental health education is an indispensable part of College Students' study and life. Mental health education for students to improve their ability to adapt to society and life, cultivate students to establish a good psychological quality and the psychological quality, promote students' practice ability, mental ability, analysis ability, innovation ability, and the coordinated development, and improve the educational purpose, aim and development has a very important role. Strengthening the mental health education of college students is an important measure to implement the quality education in the long run, and it is an important part of the education in Colleges and universities. The in view of the problems existed in college students' psychological health education proposed under the new situation of College Students' psychological health education strategies, has an 
important role to strengthen quality education, to promote the development of physical and mental health of college students, socialist qualified builders and successors in terms of culture.

\section{References}

[1] S. X. Zhou, "The application of mental health education in the ideological and political education of College Students," Journal of China Youth University for Political Sciences, vol. 33, no. 4, pp. 59-62, 2015.

[2] C. H. Zhao, "On the innovation of College Students' mental health education model," Heilongjiang Researches on Higher Education, vol. 33, no. 5, pp. 103-105, 2014.

[3] T. Wu, J. Y. Wang, L. X. Xu, "Construction of College Students' mental health education system from the perspective of synergy, vol. 51, no. 10, pp. 53-55, 2015.

[4] J. P. Hu, "Current situation and countermeasures of college students' network psychological health education in the new media background," China Adult Education, vol. 23, no. 24, pp. 52-55, 2014.

[5] M. Sun, "Some thoughts on strengthening and improving the mental health education of contemporary college students," China Adult Education, vol. 24, no. 11, pp. 64-66, 2015.

[6] H. Yang, X. X. Wang, "Research on the mental health education of college students in the new media era," School party construction and Ideological Education, vol. 33, no. 12, pp. 82-83, 2015.

[7] W. X. Yu, "Analysis of College Students' psychological health status and Educational Countermeasures," Education and Vocation, vol. 99, no. 11, pp. 68-70, 2015.

[8] X. L. Liu, H. Q. Xing, "A Probe into the Mental Health Education of Poor College Students," Theory and Practice of Education, vol. 35, no. 3, pp. 41-42, 2015. 